\title{
Positive and Negative Interactions with Humans Concurrently Affect Vervet Monkey (Chlorocebus pygerythrus) Ranging Behavior
}

\author{
Harriet R. Thatcher, et al. [full author details at the end of the article]
}

Received: 10 January 2019 / Accepted: 21 June 2019 /Published online: 9 August 2019

(C) The Author(s) 2019

\begin{abstract}
Many nonhuman primates adjust their behavior and thrive in human-altered habitats, including towns and cities. Studying anthropogenic influences from an animal's perspective can increase our understanding of their behavioral flexibility, presenting important information for human-wildlife cohabitation management plans. Currently, research on anthropogenically disturbed wildlife considers either positive or negative aspects of human-wildlife encounters independently, highlighting a need to consider potential interactions between both aspects. Vervet monkeys (Chlorocebus pygerythrus) are a suitable species to address this gap in research as they tolerate urbanization; however, they are understudied in urban landscapes. We conducted this study in KwaZulu-Natal, South Africa, where vervet monkeys are commonly found throughout the anthropogenic landscape. Here we determined, from a monkey's perspective, how the frequency and nature of human-monkey interactions, both positive (human food availability) and negative (human-monkey aggression), affected vervet monkey ranging patterns in an urban environment. We assessed the movement patterns of three groups of urban vervet monkeys over 1 year, analyzing both $95 \%$ and $50 \%$ kernel density estimates of their home ranges alongside daily path lengths and path sinuosities every month using generalized linear mixed models. Overall, we found that human interactions within the urban landscape affected all measures of ranging to some degree. The core home ranges of vervet monkeys increased with a higher rate of positive human encounters, and their total home range increased with an interaction of both positive and negative human encounters. Furthermore, vervet monkeys were less likely to respond (i.e., increase daily path length or path sinuosity) to human aggression when food rewards were high, suggesting that effective management should focus on reducing human food foraging opportunities. Our results highlight the complex interplay between positive and negative aspects of urban living and provide guidance for managers of human-nonhuman primate interactions.
\end{abstract}

Keywords Anthropogenic effects $\cdot$ Chlorocebus pygerythrus $\cdot$ Daily path length $\cdot$ Humanwildlife interactions · Path sinuosity - Urban landscape

Handling Editor: Joanna M. Setchell. 


\section{Introduction}

Anthropogenic pressures are a growing issue for wildlife management, particularly with a global increase in the rate of anthropogenic changes to land use, including urbanization (McKinney 2008). As anthropogenic disturbance increases, so too does research on wildlife living in anthropogenically altered landscapes (McKinney 2008). Almost all wildlife live in an environment that is subject to some level of anthropogenic disturbance (Soulsbury and White 2015). The effects of such environmental change on wildlife vary dramatically with the nature of the disturbance (McKinney 2008), such as habitat loss (Estrada and Coates-Estrada 1996), tourism (Brennan et al. 1985; Fuentes et al. 2007; McKinney 2014), or modified landscapes (Fuentes and Hockings 2010). Understanding how wildlife can adapt behaviorally in an anthropogenically disturbed environment is essential to provide guidance for humanwildlife cohabitation and conservation management (Dickman 2010; Hockings et al. 2015; Nowak and Lee 2013).

Human-wildlife cohabitation and the associated interactions can be beneficial and/ or detrimental to an animal depending on its flexibility (Ditchkoff et al. 2006; McKinney 2008). Although terminology used in human-wildlife research is moving away from using loaded terms such as "conflict" and "raiding" (Humle and Hill 2016), there is still a tendency to focus on negative rather than positive human-wildlife interactions (Graham et al. 2005). Furthermore, most studies of negative effects on wildlife measure the avoidance of human inhabited areas, rather than directly measuring the effects of human aggression toward wildlife (Gehrt et al. 2009; Graham et al. 2009; Prokopenko et al. 2017). Currently, there is a bias in the literature to focus on these positive and negative interactions from a human perspective; however, to understand urban wildlife, possible costs and benefits for wildlife should also be considered (Soulsbury and White 2015).

Research into the behavioral flexibility of nonhuman primate species (herein known as primates) in the anthropogenic landscape is increasing (McLennan et al. 2017). For many primates, human-modified landscapes in urbanized areas provide increased access to anthropogenic food sources (Cancelliere et al. 2018); but where primates feed on human crops and food, this foraging technique is often viewed as a "problem" behavior for humans rather than a beneficial foraging strategy for primates (Riley 2008; Strum 2010). From a primate's perspective, using the urban landscape has many costs, such as increased aggression from humans (Beisner et al. 2015) and increased parasite load (Thatcher et al. 2018). Most literature on human-primate cohabitation focuses on either positive or negative aspects of human-wildlife interactions (McLennan et al. 2017; Seoraj-Pillai and Pillay 2016; Woodroffe et al. 2005). No study has yet assessed how human food availability and human-wildlife aggression interact to affect ranging patterns.

Some primate species, such as macaques (Macaca spp.), baboons (Papio spp.), and vervet monkeys (Chlorocebus pygerythrus) (Chapman et al. 2016; Priston and McLennan 2013; Strum 1994; Thatcher et al. 2018) can adjust and thrive under the challenging pressures of the changing anthropogenic landscape. Among primates, much research has focused on anthropogenic features that influence habitat selection, e.g., a preference for increased food resources (Bryson-Morrison et al. 2016, 2017; Hoffman and O'Riain 2012a) and avoidance of noise disturbance (Duarte et al. 2011). 
Studies have also shown how anthropogenic influences affect ranging patterns, generally highlighting that greater anthropogenic disturbance reduces home range size (Altmann and Muruth 1988; Hoffman and O'Riain 2011, 2012b; McKinney 2011; Riley 2008; Saj et al. 1999; Sha and Hanya 2013). Despite the plethora of research on the ranging patterns of anthropogenically affected primates, there is a paucity of research on urban dwelling primates. Knowledge of ranging patterns of urban primates is limited to a few studies (Klegarth et al. 2017; Patterson et al. 2019). For example, one study considered two geographically distant macaque species, showing they responded to anthropogenic disturbance (categorized landscapes) in similar ways: reducing home range size and daily path length (Klegarth et al. 2017).

Vervet monkeys can thrive in urban landscapes (Patterson et al. 2017, 2018, 2019; Saj et al. 1999), exhibiting behavioral flexibility to adapt to anthropogenic disturbance (Chapman et al. 2016; Thatcher et al. 2019). It is therefore an ideal species to examine the effect of variation in human-wildlife interactions on ranging behavior. Despite prior research on vervet monkey home range patterns (De Moor and Steffens 1972; Herzog et al. 2014; Isbell et al. 1991; Willems et al. 2009; Willems and Hill 2009), relatively little is known about the ranging behavior of urban vervet monkeys (Patterson et al. 2019), which is important for developing appropriate management plans (Beckmann and Berger 2003; Hoffman and O'Riain 2012a).

In this study, we tested the hypothesis that anthropogenic influences from a monkey's perspective, both positive (human food availability) and negative (human-monkey aggression), influenced vervet monkey ranging patterns in an urban environment. Prior studies have shown that increased access to calorie-rich human food resources reduces time spent moving in pursuit of food (Hoffman and O'Riain 2011; Klegarth et al. 2017); we therefore predicted that urban vervet monkey home ranges would decrease with increased access to calorie-rich food resources in the urban environment. Furthermore, previous research has shown that time spent moving increased after increased human-monkey aggression directed toward vervet monkeys (Thatcher et al. 2019), and we predicted that daily path length and path sinuosity (directness of path) would be greater in groups that experienced more negative interactions with people.

\section{Methods}

\section{Study Population}

We conducted our study at Simbithi eco-estate, a private gated estate in Ballito, Durban north coast, KwaZulu-Natal, South Africa $\left(29.5140^{\circ} \mathrm{S}, 31.2197^{\circ}\right.$ E) (Fig. 1). The 4.7$\mathrm{km}^{2}$ estate was previously two sugarcane farms that were converted to an ecologically considerate urban housing development (Simbithi eco-estate 2017; Peter Coulon pers. comm.). The estate contains a variety of housing options along with leisure facilities, restaurants, an equestrian center, a golf course, and small areas of manmade riverine coastal forest. The estate is securely fenced off from the surrounding area; however, monkeys can leave through small gaps in the fencing structure. Housing and anthropogenic structures within the estate are specifically designed to create wildlife corridors and only "natural fencing" such as plants can be used to define housing borders. 
Although discouraged by the estate management, humans feed vervet monkeys at residential homes and leisure facilities (Harriet Thatcher pers. obs.). Groups of monkeys often obtain human food from residential kitchens, refuge sites, and leisure facilities. Using McKinney's (2015) anthropogenic disturbance classification system, we coded the field site as $\mathrm{HG}_{3} \mathrm{LC}_{5}$, $(\mathrm{H}$ : nonprotected high human population density urban area; $\mathrm{G}_{3}:>25 \%$ of total diet is stolen or provisioned human foods, varying between groups; L: interactions with locals and researchers daily including provisioning; $\mathrm{C}_{5}$ : reduced predation but association with human conflict).

Seven groups of vervet monkeys live within Simbithi eco-estate; we studied three of these groups that used the housing estate, selecting those that confined their activity to the estate to ensure observer safety (because of high crime rates in the local area). Group size varied from 23 to 42 individuals, with mean ( $\pm \mathrm{SD}$ ) counts as follows:

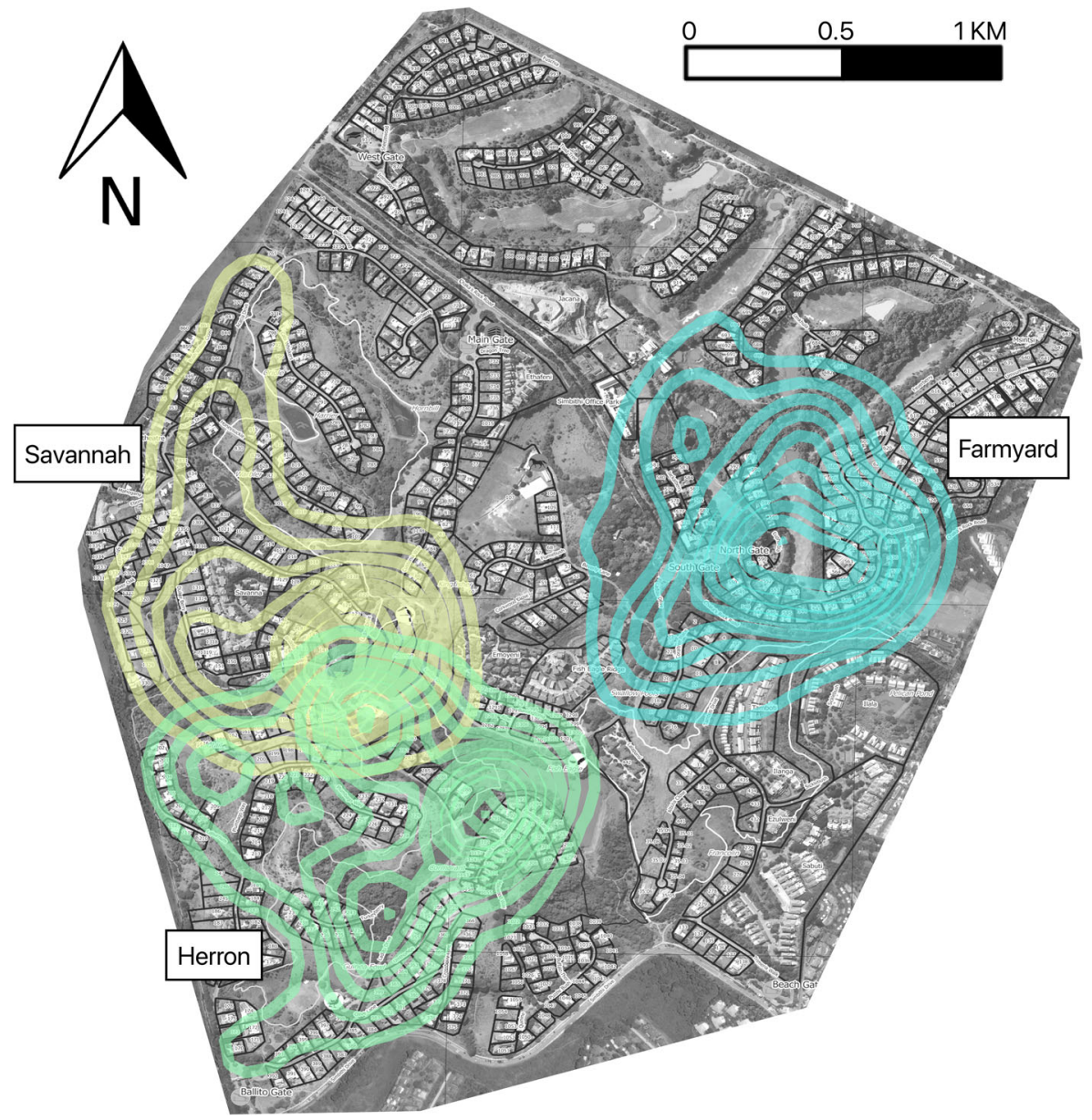

Fig. 1 Map of Study Site Simbithi Eco-Estate, Ballito, Durban North Coast, KwaZulu-Natal, South Africa used from March 2016 to March 2017. Black Outlined Shapes Represent Residential Plots within the Estate. Colored Rings Show the Annual Kernel Density Estimates; Rings Represent Home Range in Increments of $10 \%$ Per Group $($ blue $=$ Farmyard, green $=$ Herron, yellow $=$ Savannah). Base Map Redrawn from http://www. simbithi.co.za/. 
Farmyard group ( $23 \pm 0.25)$ : 4 males, 10 females, 9 juveniles; Heron group (42 \pm 1.03$)$ : 5 males, 14 females, 23 juveniles; and Savannah group $(25 \pm 0.44): 4$ males, 10 females, 11 juveniles. Living in an urban area, monkeys were already habituated to the presence of humans $(10 \mathrm{~m})$. This was the first behavioral study of these vervet monkeys, so their history was unknown.

\section{Data Collection}

We conducted all fieldwork following three groups over 12 mo from March 2016 to February 2017. We followed each group on average for 4 days/mo, equalizing follows across groups (mean $\pm \mathrm{SD}$ : Farmyard $3.9 \pm 0.57$ days; Heron $4.1 \pm 0.51$; Savannah $4 \pm 0.69$ ). We followed groups from dawn to dusk, recording the group location at sunrise at their sleep site and then continuing to record their location every $30 \mathrm{~min}$ standing at the center of the group with a hand-held global positioning system (GPS) (Dakota 20, Garmin Inc., USA). We used 30-min intervals to calculate four ranging measures: total home range $(95 \%)$, core home range $(50 \% \mathrm{KDE})$, path length, and path sinuosity. We chose 30-min intervals to adequately reduce autocorrelation while still representing biologically realistic data (Asensio et al. 2012).

We used all-occurrence sampling to record all interactions between humans and vervet monkeys during dawn-to-dusk daily follows. We identified a human-related encounter as any occasion when human(s) and at least one vervet monkey interacted. We recorded encounters as positive (human food) and/or negative (human-monkey aggression). We considered a positive event as terminated once all the human food had been consumed and recorded new events only when there had been no interactions/ human food consumption for at least $20 \mathrm{~min}$. Negative human encounters included any form of aggression from humans toward vervet monkeys. We considered a negative event to be over once all parties had retreated out of visual contact of each other and we recorded a new event when there had been no encounter in the preceding $20 \mathrm{~min}$. We calculated a rate (frequency/h) for both positive and negative human encounters per group each month.

\section{Data Analyses}

We screened GPS data from each group for outliers, removing 2 days of data for the Savannah group because of positional errors (one in June and one in August). We summarized ranging data using four measures. To assess home range, we considered total home range area (95\% isopleths) and core area (50\% isopleths) (Laver and Kelly 2008) and analyzed GPS points using the kernel density estimator (KDE) (Seaman and Powell 1996). We measured KDE using the adehabitat package in R applying the kernel estimator function kernelUD (Calenge 2006). We calculated daily path length for each group by summing the distances between successive GPS locations using the saga processing toolbox in QGIS (QGIS 2015). Finally, we assessed the directness of travel routes by calculating the path sinuosity. We used QGIS to obtain the distance between the first and last point of the day, giving us the most direct path length. We calculated path sinuosity by dividing the daily path length by the direct path length (e.g., monkeys that used a less direct path had a higher sinuosity) (Benhamou 2004). 
We conducted all analyses using R statistical software version 3.3.2 (R project 2013) with the significance level set at $P<0.05$. We modeled each ranging measure separately, using monthly values for total and core home range area $(N=36)$ and mean monthly values for daily path length and sinuosity $(N=36)$. Our main results did not change when we used monthly rather than daily values for path calculations; we therefore used monthly path values so our results were comparable with the literature. We used the same model structure for all four ranging measures including mean monthly group size, positive human encounters and negative human encounters as fixed effects, as well as including an interaction between positive and negative human encounters. To account for repetition in the data set we included month as a random effect. Monthly we tested data graphically in $\mathrm{R}$ using the lctools package to ensure data were not autocorrelated (Kalogirou 2016); all responses fell within the confidence intervals, showing that data were not temporally autocorrelated. We calculated the variation inflation factor (VIF) of each predictor for inclusion in our model using the car package (Fox and Weisberg 2011), setting the VIF limit at $P<3$ (Zuur et al. 2010). Dependent variables were not normally distributed according to a Shapiro-Wilk test $(P<0.05)$ and visual inspection using QQ plots (Ghasemi and Zahediasl 2012). We therefore used generalized linear mixed models (GLMMs) with a gamma distribution, allowing us to model nonnormally distributed data with a random effect. We specified four GLMMs using the lme4 package (Bates 2010).

Owing to our small sample size $(N=36)$ in a model with four predictors, we bootstrapped our model to obtain confidence intervals (CIs), resampling 1000 times to strengthen the model robustness (Yung and Chan 1999). Furthermore, we used a Kenward-Roger correction in the afex package in R (Singmann et al. 2015) to minimize small sample size bias and guard against inflation of Type I error rates (McNeish 2017; Stroup 2015). We present the Kenward-Roger $P$ values as well as the bootstrapped CIs; if the upper and lower CIs straddled 0 then we did not consider the variable significant. We assessed the fit of each model by graphically checking residuals for normal distribution and to check the assumptions of our model were not violated.

Data Availability The data sets analyzed during the current study are available from the corresponding author on reasonable request.

\section{Ethical Note}

This study was purely observational. We adhered to the legal requirements of South Africa for the ethical treatment of primates under Liverpool John Moores University ethical permit number NK_HT/2017-6. The authors declare that they have no conflict of interest.

\section{Results}

The three study groups varied in group size, total and core home range size, daily path length, and sinuosity, as well as in the frequency of positive and negative incidences with humans (Fig. 1, Table I). 
Table I Mean monthly ranging metrics + SD for three study groups of urban vervet monkeys, Simbithi ecoestate, KwaZulu-Natal, South Africa, Märch 2016-March 2017

\begin{tabular}{lcllllll}
\hline Study group & Group size & $\begin{array}{l}\text { Positive } \\
\text { human } \\
\text { encounters }\end{array}$ & $\begin{array}{l}\text { Negative } \\
\text { human } \\
\text { encounters }\end{array}$ & $\begin{array}{l}\text { Total home } \\
\text { range }\left(\mathrm{km}^{2}\right)\end{array}$ & $\begin{array}{l}\text { Core home } \\
\text { range }\left(\mathrm{km}^{2}\right)\end{array}$ & $\begin{array}{l}\text { Path length } \\
(\mathrm{km})\end{array}$ & $\begin{array}{l}\text { Path } \\
\text { sinuosity }\end{array}$ \\
\hline Farmyard & $23 \pm 0.25$ & $0.33 \pm 0.71$ & $0.12 \pm 0.06$ & $2.97 \pm 0.31$ & $0.29 \pm 0.31$ & $4.14 \pm 3.51$ & $2.77 \pm 2.77$ \\
Heron & $42 \pm 1.03$ & $1.08 \pm 0.71$ & $0.35 \pm 0.21$ & $1.83 \pm 1.13$ & $0.51 \pm 0.50$ & $6.16 \pm 3.27$ & $8.41 \pm 4.83$ \\
Savannah & $25 \pm 0.44$ & $0.42 \pm 0.27$ & $0.09 \pm 0.06$ & $3.17 \pm 0.22$ & $0.27 \pm 0.21$ & $3.53 \pm 2.10$ & $3.30 \pm 2.36$ \\
\hline
\end{tabular}

\section{Home Range}

There was a significant positive interaction effect between the effects of positive and negative human encounters on total monthly urban vervet monkey home ranges (Fig. 2a, Table II). Increased positive human encounters were related to a decrease in home range size; however, increased negative human encounters weakened this effect, and together a combination of higher positive and negative human encounters increased home range size. Core monthly home range size was significantly larger for urban vervet monkeys that experienced higher levels of positive human encounters (Fig. 3, Table III).

\section{Daily Path Length}

There was a significant negative interaction effect on vervet monkey daily path length (Fig. 2b, Table IV). Negative human encounters were associated with increased daily path length when positive encounters were low, but when monkeys experienced both high negative and high positive events, they were less likely to move on and daily path length did not increase.

\section{Path Sinuosity}

There was a significant negative interaction effect between positive and negative human encounters on vervet monkey path sinuosity; when positive human encounters

Table II Results of GLMM model of factors influencing the total home range area (95\% KDE) of urban vervet monkeys, Simbithi eco-estate, KwaZulu-Natal, South Africa, March 2016-March 2017

\begin{tabular}{llllll}
\hline & Estimate & Standard error & $P$ value & Upper CI & Lower CI \\
\hline Intercept & 4.45 & 1.22 & $<0.001$ & 3.91 & 6.83 \\
Negative human encounters & -7.78 & 1.65 & $<0.001$ & -0.55 & -1.71 \\
Positive human encounters & -8.84 & 0.71 & $<0.001$ & -0.47 & -2.66 \\
$\begin{array}{l}\text { Negative human encounters } \times \text { Positive } \\
\quad \text { human encounters }\end{array}$ & $\mathbf{5 . 4 9}$ & $\mathbf{0 . 4 1}$ & $\mathbf{0 . 0 0 1}$ & $\mathbf{2 . 4 8}$ & $\mathbf{0 . 0 1}$ \\
\begin{tabular}{l}
$\quad$ Group size \\
\hline
\end{tabular} & 0.02 & 1.77 & 0.725 & 0.03 & 2.09 \\
\hline
\end{tabular}

Bolded values are significant. We did not consider main effects significant if the interaction was also significant 



Positive human encounters per hour

Fig. 2 Interaction between mean Monthly Rate of Negative Human Encounters Per Hour and the Mean Monthly Rate of Positive Human Encounters Per Hour on the Ranging Patterns of Three Groups of Urban Vervet Monkeys at Simbithi Eco-Estate, KwaZulu-Natal, South Africa, March 2016-March 2017.

were low, negative human encounters increased path sinuosity; however, increasing positive encounters weakened this effect (Fig. 2c, Table V). Vervet monkey group size had a significant positive effect on path sinuosity (Table V).

\section{Discussion}

All four measures of urban vervet monkey ranging patterns were influenced by anthropogenic disturbance. Furthermore, the interaction effect between both positive and negative human encounters strongly influenced vervet monkeys' movement patterns, highlighting their behavioral flexibility to anthropogenic influences.

The interaction between positive and negative human encounters indicated that increasing positive human encounters decreased vervet monkey total home range size; however, increasing negative human encounters weakened this effect. Previous literature generally suggests home range decreases in anthropogenically disturbed primates are a result of increased access to human resources (Klegarth et al. 2017; Saj et al. 1999). However, our results were not fully supportive of previous research, likely owing to our interaction between positive and negative aspects of urban living for vervet monkeys, reinforcing the need to consider the nature and frequency of human-primate interactions. We therefore suggest that the increasing total home range size, seen in this study, could be an avoidance strategy to reduce the likelihood of human aggression when it cooccurs with increased human food availability. Our work supports previous research on wildlife in anthropogenic landscapes that suggests wildlife alter their ranging behavior to avoid areas due to increased risk of human conflict (African elephants, Loxodonta africana: Graham et al. 2009; elk, Cervus elaphus: Prokopenko et al. 2017; Sulawesi Tonkean macaques, Macaca tonkeana: Riley 208).

We found that vervet monkey core home range increased with a higher rate of positive human encounters. These core home range findings contrast with previous research that suggests core areas decrease with anthropogenic resources (Hoffman and O'Riain 2011; Klegarth et al. 2017). Nevertheless, our results support the hypothesis that vervet 


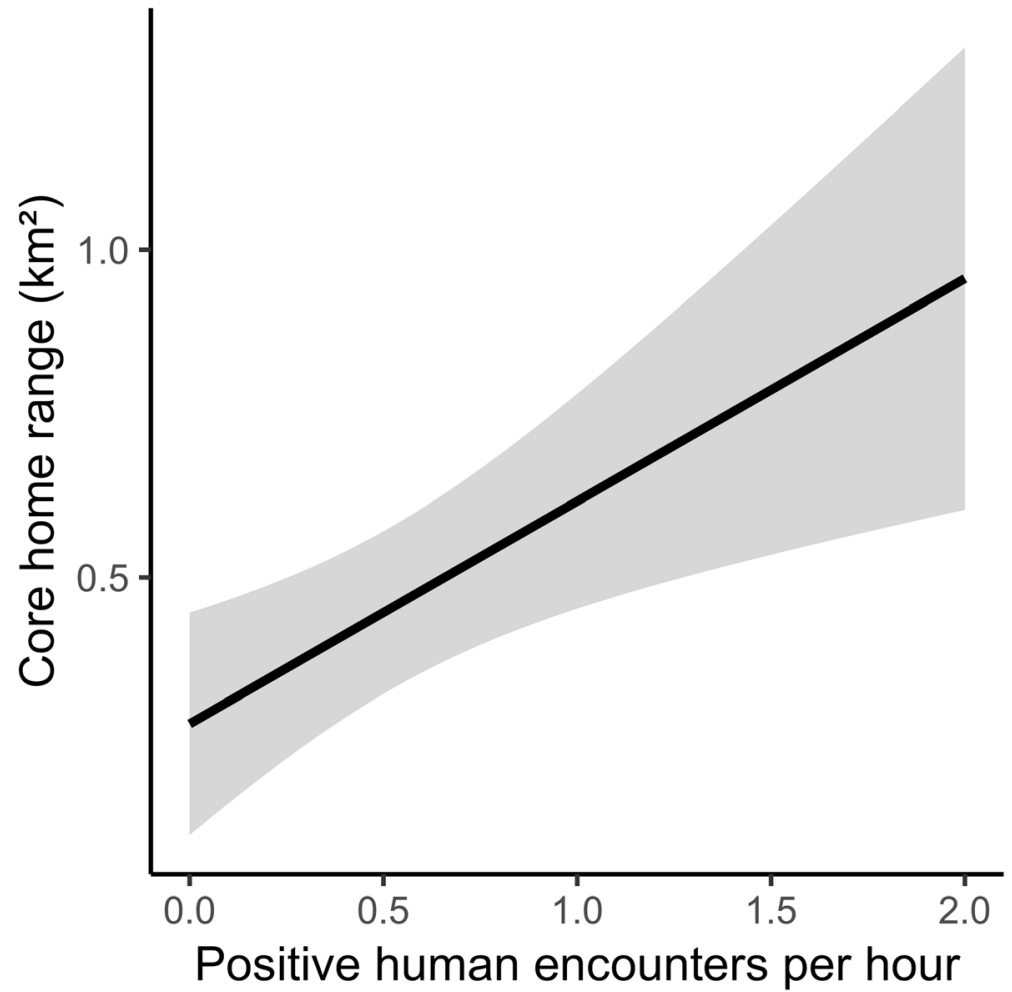

Fig. 3 Effect of Positive Human Encounters Per Hour on the Core Home Range of Three Groups of Urban Vervet Monkeys at Simbithi Eco-Estate, KwaZulu-Natal, South Africa, March 2016-March 2017.

monkeys avoid areas of human conflict and is complementary to research on Tonkean macaques (Macaca tonkeana) that has shown that they express flexibility in anthropogenically disturbed habitats, by ranging further to where known resources are predictably available (Riley 2008). It is possible that vervet monkeys in this study ranged further, to increase consumption of human food resources at predictable locations, and thus increased their core home ranges. Increased energetic costs of movement are likely

Table III Results of GLMM model of factors influencing the core range area (50\% KDE) of urban vervet monkeys, Simbithi eco-estate, KwaZulu-Natal, South Africa, March 2016-March 2017

\begin{tabular}{llllll}
\hline & Estimate & Standard error & $P$ value & Upper CI & Lower CI \\
\hline Intercept & -2.74 & 0.47 & $<0.001$ & -0.66 & -5.03 \\
Negative human encounters & 1.22 & 0.66 & 0.061 & -0.91 & 0.56 \\
$\begin{array}{l}\text { Positive human encounters } \\
\text { Negative human encounters } \times \text { Positive }\end{array}$ & $\mathbf{2 . 4 5}$ & $\mathbf{0 . 9 7}$ & $\mathbf{0 . 0 1 8}$ & $\mathbf{3 . 5 1}$ & $\mathbf{1 . 9 0}$ \\
$\quad$ human encounters & -1.20 & 0.68 & 0.083 & -1.62 & 1.28 \\
Group size & & & 0.546 & -0.11 & 0.06 \\
\hline
\end{tabular}

Bolded values are significant. We did not consider main effects significant if the interaction was also significant 
Table IV Results of GLMM model of factors influencing the daily path length $(\mathrm{km})$ of urban vervet monkeys, Simbithi eco-estate, KwaZulu-Natal, South Africa, March 2016-March 2017

\begin{tabular}{llllll}
\hline & Estimate & Standard error & $P$ value & Upper CI & Lower CI \\
\hline Intercept & 1.06 & 0.01 & 0.078 & 0.03 & 1.75 \\
Negative human encounters & -0.01 & 0.01 & 0.274 & -0.81 & 0.81 \\
Positive human encounters & -0.01 & 0.01 & 0.139 & -0.81 & 0.77 \\
$\begin{array}{l}\text { Negative human encounters } \times \text { Positive } \\
\quad \text { human encounters }\end{array}$ & $\mathbf{- 0 . 0 5}$ & $\mathbf{0 . 0 1}$ & $\mathbf{< . 0 0 1}$ & $\mathbf{- 0 . 9 2}$ & $\mathbf{- 0 . 8 4}$ \\
\begin{tabular}{l} 
Group size \\
\hline
\end{tabular} & 0.26 & 0.01 & 0.051 & -0.57 & 0.83 \\
\hline
\end{tabular}

Bolded values are significant. We did not consider main effects significant if the interaction was also significant

outweighed by the benefit of high calorific human food (e.g., bread, cake, pizza). We originally predicted that core and total home range would decrease under anthropogenic pressures; however, our core home range result did not support this prediction and our total home range results only partially support our prediction. Crucially, our results highlight the need to quantitatively measure multiple aspects of anthropogenic disturbance to understand the multiple facets that influence urban primate behavioral ecology.

We found a negative interaction between the effects of positive and negative human encounters on urban vervet monkey daily path length. Although human aggression was related to increased daily path length, the benefit of human food resources appeared to offset this increase, suggesting a decreased likelihood of moving on. Our results support previous findings (Klegarth et al. 2017; Saj et al. 1999) that anthropogenically disturbed primates decrease daily movement due to increased anthropogenic resources. Further, our results show that vervet monkeys' movement increased with humanmonkey aggression, yet positive human encounters weakened this effect. Our findings support previous research that shows vervet monkeys are less likely to move in response to human aggression if human food resources are available (Thatcher et al. 2019). Our results further highlight the complex interaction between positive and

Table V Results of GLMM model of factors influencing the path sinuosity of urban vervet monkeys, Simbithi eco-estate, KwaZulu-Natal, South Africa, March 2016-March 2017

\begin{tabular}{llllll}
\hline & Estimate & Standard error & $P$ value & Upper CI & Lower CI \\
\hline Intercept & 1.24 & 0.19 & 0.001 & 3.91 & 6.96 \\
Negative human encounters & 0.06 & 0.11 & 0.581 & -0.49 & 1.73 \\
Positive human encounters & 0.28 & 0.10 & 0.005 & 0.49 & 2.67 \\
$\begin{array}{l}\text { Negative human encounters * Positive } \\
\quad \text { human encounters }\end{array}$ & $\mathbf{- 0 . 0 9}$ & $\mathbf{0 . 1 1}$ & $\mathbf{0 . 0 4 2}$ & $\mathbf{- 2 . 6 5}$ & $\mathbf{- 0 . 0 6}$ \\
Group size & $\mathbf{0 . 3 1}$ & $\mathbf{0 . 0 9}$ & $\mathbf{0 . 0 0 1}$ & $\mathbf{0 . 0 8}$ & $\mathbf{2 . 1 1}$ \\
\hline
\end{tabular}

Bolded values are significant. We did not consider main effects significant if the interaction was also significant 
negatives aspects of urban living, implying an "attraction-avoidance" scale for urban primates. Overall, our findings for daily path length suggest that vervet monkeys' movement is highly dependent on the availability of high-value food resources. Crucially, we suggest that increased human aggression appears to be ineffective in reducing human food foraging strategies in vervet monkeys when there is increased access to human food resources.

Our vervet monkey path sinuosity measures showed similar findings to daily path length. Negative human encounters were related to increased path sinuosity; however, with increasing positive human encounters this effect weakened, and paths became more direct. Again, our results support previous literature on vervet monkey movement, suggesting that vervet monkeys' movement was reduced with increased access to high-value food (Saj et al. 1999; Thatcher et al. 2019). Interestingly, when there were no negative human encounters, a higher rate of positive human encounters was related to increased path sinuosity. Although this finding somewhat contrasts with our prior argument and previous research that suggests human resources should decrease primate movement, some studies have shown primates increase travel to improve spatial feeding strategies (Riley 2008; Sha and Hanya 2013). It is possible that increased path sinuosity may be a consequence of vervet monkeys being more exploratory in their spatial feeding when rewards are high (positive human encounters) and risks are low (negative human interactions). Results for path sinuosity indicate that obtaining highvalue human-derived food is a beneficial foraging strategy, most likely because of its calorific return (Cancelliere et al. 2018; Strum 2010) and that vervet monkeys use flexible strategies depending on human influences. These findings highlight the complex association of benefits and costs for primates residing in urban areas.

We can use our results to make recommendations for more effective human-primate management plans. Our results show that vervet monkeys are less likely to respond (i.e., increase daily path length or path sinuosity) to human aggression when food rewards are high. We therefore suggest that to minimize negative human-wildlife relations management plans should focus on reducing access to anthropogenic resources in any form. Nevertheless, the human-primate interface encompasses multiple facets (Nyhus 2016). Future research should therefore consider measures of positive and negative interactions from a human perspective, to increase our understanding of urban primate ecology, as well as increase the likelihood of successful management strategies (Dickman 2010).

We originally predicted that urban vervet monkey home ranges would decrease with increased access to calorie-rich food resources in the urban environment. Although our findings do not fully support our prediction, our results highlight that ranging patterns in urban vervet monkey groups are strongly affected by the nature and frequency of anthropogenic influences within the urban landscape. In conclusion, our findings emphasize the importance of considering the previously overlooked interaction of positive and negative characteristics of urban living for vervet monkeys, suggesting an attraction-avoidance scale within the anthropogenic landscape.

Acknowledgments We thank Simbithi eco-estate for allowing us to conduct our research at their premises. We also thank Liverpool John Moores University, the University of KwaZulu-Natal, and the National Research Foundation (ZA) for their support during this period. This work was supported by an Erasmus Mundus AESOP (A European and South African Partnership on Heritage and Past) grant (ES15DM0025) to 
HT. We also thank Marina Cords, anonymous reviewers, and Jo Setchell for their constructive comments on drafts of the manuscript.

Author's Contributions HRT, CTD, and NFK conceived and designed the study. HRT conducted the fieldwork. HRT and NFK analyzed the data. HRT, CTD, and NFK wrote the manuscript.

\section{Compliance with Ethical Standards}

Conflicts of Interest The authors declare that they have no conflict of interest.

Open Access This article is distributed under the terms of the Creative Commons Attribution 4.0 International License (http://creativecommons.org/licenses/by/4.0/), which permits unrestricted use, distribution, and reproduction in any medium, provided you give appropriate credit to the original author(s) and the source, provide a link to the Creative Commons license, and indicate if changes were made.

\section{References}

Altmann, J., \& Muruth, P. (1988). Differences in daily life between semiprovisioned and wiId-feeding baboons. American Journal of Primatology, 15, 213-221.

Asensio, N., Schaffner, C. M., \& Aureli, F. (2012). Variability in core areas of spider monkeys (Ateles geoffroyi) in a tropical dry forest in Costa Rica. Primates, 53(2), 147-156.

Bates, D. M. (2010). lme4: Mixed-effects modeling with R. New York: Springer Science+Business Media.

Beckmann, J. P., \& Berger, J. (2003). Rapid ecological and behavioural changes in carnivores: The responses of black bears (Ursus americanus) to altered food. Journal of Zoology, 261(2), 207-212.

Beisner, B. A., Heagerty, A., Seil, S. K., Balasubramaniam, K. N., Atwill, E. R., Gupta, B. K., Tyagi, P. C., Chauhan, N. P. S., Bonal, B. S., Sinha, P. R., \& McCowan, B. (2015). Human-wildlife conflict: Proximate predictors of aggression between humans and rhesus macaques in India. American Journal of Physical Anthropology, 156(2), 286-294.

Benhamou, S. (2004). How to reliably estimate the tortuosity of an animal's path: Straightness, sinuosity, or fractal dimension? Journal of Theoretical Biology, 229(2), 209-220.

Brennan, E. J., Else, J. G., \& Altmann, J. (1985). Ecology and behaviour of a pest primate: Vervet monkeys in a tourist-lodge habitat. African Journal of Ecology, 23(1), 35-44.

Bryson-Morrison, N., Matsuzawa, T., \& Humle, T. (2016). Chimpanzees in an anthropogenic landscape: Examining food resources across habitat types at Bossou, Guinea, West Africa. American Journal of Primatology, 78(12), 1237-1249.

Bryson-Morrison, N., Tzanopoulos, J., Matsuzawa, T., \& Humle, T. (2017). Activity and habitat use of chimpanzees (Pan troglodytes verus) in the anthropogenic landscape of Bossou, Guinea, West Africa. International Journal of Primatology, 38(2), 282-302.

Calenge, C. (2006). The package "adehabitat" for the R software: A tool for the analysis of space and habitat use by animals. Ecological Modelling, 197(3-4), 516-519.

Cancelliere, E. C., Chapman, C. A., Twinomugisha, D., \& Rothman, J. M. (2018). The nutritional value of feeding on crops: Diets of vervet monkeys in a humanized landscape. African Journal of Ecology, 56(2), $160-167$.

Chapman, C.A., Twinomugisha, D., Teichroeb, J.A., Valenta, K., Sengupta, R., et al. (2016). How do primates survive among humans? Mechanisms employed by vervet monkeys at Lake Nabugabo, Uganda. In M. Waller (Ed.), Ethnoprimatology: Primate conservation in the 21st century. Developments in primatology: Progress and prospects. Cham, Switzerland: Springer International.

De Moor, P. P., \& Steffens, F. E. (1972). The movements of vervet monkeys (Cercopithecus aethiops) within their ranges as revealed by radio-tracking. The Journal of Animal Ecology, 677-687.

Dickman, A. J. (2010). Complexities of conflict: The importance of considering social factors for effectively resolving human-wildlife conflict. Animal Conservation, 13(5), 458-466.

Ditchkoff, S. S., Saalfeld, S. T., \& Gibson, C. J. (2006). Animal behavior in urban ecosystems: Modifications due to human-induced stress. Urban Ecosystems, 9(1), 5-12. 
Duarte, M. H. L., Vecci, M. A., Hirsch, A., \& Young, R. J. (2011). Noisy human neighbours affect where urban monkeys live. Biology Letters, 7(6), 840-842.

Estrada, A., \& Coates-Estrada, R. (1996). Tropical rain forest fragmentation and wild populations of primates at Los Tuxtlas, Mexico. International Journal of Primatology, 17(5), 759-783.

Fox, J., \& Weisberg, S. (2011). Multivariate linear models in R. An R Companion to Applied Regression. Los Angeles: Thousand Oaks.

Fuentes, A., \& Hockings, K. J. (2010). The ethnoprimatological approach in primatology. American Journal of Primatology, 847(72), 841-847.

Fuentes, A., Shaw, E., \& Cortes, J. (2007). Qualitative assessment of macaque tourist sites in Padangtegal, Bali, Indonesia, and the upper rock nature reserve, Gibraltar. International Journal of Primatology, 28(5), 1143-1158.

Gehrt, S. D., Anchor, C., \& White, L. A. (2009). Home range and landscape use of coyotes in a metropolitan landscape: Conflict or coexistence? Journal of Mammalogy, 90(5), 1045-1057.

Ghasemi, A., \& Zahediasl, S. (2012). Normality tests for statistical analysis: A guide for non-statisticians. International Journal of Endocrinology and Metabolism, 10(2), 486-489.

Graham, K., Beckerman, A. P., \& Thirgood, S. (2005). Human-predator-prey conflicts: Ecological correlates, prey losses and patterns of management. Biological Conservation, 122(2), 159-171.

Graham, M. D., Douglas-Hamilton, I., Adams, W. M., \& Lee, P. C. (2009). The movement of African elephants in a human-dominated land-use mosaic. Animal Conservation, 12(5), 445-455.

Herzog, N. M., Parker, C. H., Keefe, E. R., Coxworth, J., Barrett, A., \& Hawkes, K. (2014). Fire and home range expansion: A behavioral response to burning among savanna dwelling vervet monkeys (Chlorocebus aethiops). American Journal of Physical Anthropology, 154(4), 554-560.

Hockings, K. J., McLennan, M. R., Carvalho, S., Ancrenaz, M., Bobe, R., Byrne, R. W., Dunbar, R. I. M., Matsuzawa, T., McGrew, W. C., Williamson, E. A., Wilson, M. L., Wood, B., Wrangham, R. W., \& Hill, C. M. (2015). Apes in the Anthropocene: Flexibility and survival. Trends in Ecology and Evolution, 30(4), 215-222.

Hoffman, T. S., \& O'Riain, M. J. (2011). The spatial ecology of chacma baboons (Papio ursinus) in a humanmodified environment. International Journal of Primatology, 32(2), 308-328.

Hoffman, T. S., \& O'Riain, M. J. (2012a). Landscape requirements of a primate population in a humandominated environment. Frontiers in Zoology, 9(1), 1-17.

Hoffman, T. S., \& O’Riain, M. J. (2012b). Troop size and human-modified habitat affect the ranging patterns of a chacma baboon population in the cape peninsula, South Africa. American Journal of Primatology, 74(9), 853-863.

Humle, T., \& Hill, C. (2016). People-primate interactions: Implications for primate conservation. In S. A. Wich \& A. J. Marshall (Eds.), An introduction to primate conservation (pp. 219-240). Oxford: Oxford University Press.

Isbell, L. A., Cheney, D. L., \& Seyfarth, R. M. (1991). Group fusions and minimum group sizes in vervet monkeys (Cercopithecus aethiops). American Journal of Primatology, 25(1), 57-65.

Kalogirou, S. (2016). Lctools: Local correlation, spatial inequalities, geographically weighted regression and other tools. R package version $0.2-5$.

Klegarth, A. R., Hollocher, H., Jones-Engel, L., Shaw, E., Lee, B. P. Y. H., et al (2017). Urban primate ranging patterns: GPS-collar deployments for Macaca fascicularis and M. sylvanus. American Journal of Primatology, 79(5), 1-17.

Laver, P. N., \& Kelly, M. J. (2008). A critical review of home range studies. The Journal of Wildlife Management, 72(1), 290-298.

McKinney, M. L. (2008). Effects of urbanization on species richness: A review of plants and animals. Urban Ecosystems, 11(2), 161-176.

McKinney, T. (2011). The effects of provisioning and crop-raiding on the diet and foraging activities of human-commensal white-faced capuchins (Cebus capucinus). American Journal of Primatology, 73(5), 439-448.

McKinney, T. (2014). Species-specific responses to tourist interactions by white-faced capuchins (Cebus imitator) and mantled howlers (Alouatta palliata) in a Costa Rican wildlife refuge. International Journal of Primatology, 35(2), 573-589.

McKinney, T. (2015). A classification system for describing anthropogenic influence on nonhuman primate populations. American Journal of Primatology, 77(7), 715-726.

McLennan, M. R., Spagnoletti, N., \& Hockings, K. J. (2017). The implications of primate behavioral flexibility for sustainable human-primate coexistence in anthropogenic habitats. International Journal of Primatology, 38(2), 105-121. 
McNeish, D. (2017). Small sample methods for multilevel modeling: A colloquial elucidation of REML and the Kenward-Roger correction. Multivariate Behavioral Research, 52(5), 661-670.

Nowak, K., \& Lee, P. C. (2013). Specialist primates can be flexible in response to habitat alteration. In L. K. Marsh \& C. Chapman (Eds.), Primates in fragments: Complexity and resilience (pp. 199-211). Developments in primatology: Progress and prospects. New York: Springer Science+Business Media.

Nyhus, P. J. (2016). Human-wildlife conflict and coexistence. Annual Review of Environment and Resources, $41,143-171$.

Patterson, L., Kalle, R., \& Downs, C. (2017). A citizen science survey: Perceptions and attitudes of urban residents towards vervet monkeys. Urban Ecosystems, 20(3), 617-628.

Patterson, L., Kalle, R., \& Downs, C. (2018). Factors affecting presence of vervet monkey troops in a suburban matrix in KwaZulu-Natal, South Africa. Landscape and Urban Planning, 169, 220-228.

Patterson, L., Kalle, R., \& Downs, C. T. (2019). Living in the suburbs: Space use by vervet monkeys (Chlorocebus pygerythrus) in an eco-estate, South Africa. African Journal of Ecology. https://doi. org/10.1111/aje.12629

Priston, N. E. C., \& McLennan, M. R. (2013). Managing humans, managing macaques: Human-macaque conflict in Asia and Africa. In S. Radhakrishna, M. Huffman, \& A. Sinha (Eds.), The macaque connection. Developments in primatology: Progress and prospects. New York: Springer Science+ Business Media, 225-250.

Prokopenko, C. M., Boyce, M. S., \& Avgar, T. (2017). Extent-dependent habitat selection in a migratory large herbivore: Road avoidance across scales. Landscape Ecology, 32(2), 313-325.

QGIS. (2015). QGIS geographic information system. https://www.qgis.org/en/site/. Accessed 11 Nov 2017.

R project. (2013). R: A language and environment for statistical computing. R Foundation for Statistical Computing: Vienna, Austria. http://www.r-project.org/. Accessed 11 Nov 2017.

Riley, E. P. (2008). Ranging patterns and habitat use of Sulawesi Tonkean macaques (Macaca tonkeana) in a human-modified habitat. American Journal of Primatology, 70(7), 670-679.

Saj, T., Sicotte, P., \& Paterson, J. D. (1999). Influence of human food consumption on the time budget of vervets. International Journal of Primatology, 20(6), 974-977.

Seaman, D. E., \& Powell, R. A. (1996). An evaluation of the accuracy of kernel density estimators for home range analysis. Ecology, 77(7), 2075-2085.

Seoraj-Pillai, N., \& Pillay, N. (2016). A meta-analysis of human-wildlife conflict: South African and global perspectives. Sustainability, 9(1), 34.

Sha, J. C. M., \& Hanya, G. (2013). Diet, activity, habitat use, and ranging of two neighboring groups of foodenhanced long-tailed macaques (Macaca fascicularis). American Journal of Primatology, 75(6), 581592.

Singmann, H., Bolker, B., Westfall, J., \& Aust, F. (2015) afex: Analysis of factorial experiments. R Package. version $0.13-145$.

Soulsbury, C. D., \& White, P. C. L. (2015). Human-wildlife interactions in urban areas: A review of conflicts, benefits and opportunities. Wildlife Research, 42(7), 541-553.

Stroup, W. W. (2015). Rethinking the analysis of non-normal data in plant and soil science. Agronomy Journal, 107(2), 811-827.

Strum, S. C. (1994). Prospects for management of primate pests. Revue d'Ecologie La Terre et La Vie, 49, 295-306.

Strum, S. C. (2010). The development of primate raiding: Implications for management and conservation. International Journal of Primatology, 31(1), 133-156.

Thatcher, H. R., Downs, C. T., \& Koyama, N. F. (2018). Using parasitic load to measure the effect of anthropogenic disturbance on vervet monkeys. EcoHealth, 15, 676-681.

Thatcher, H. R., Downs, C. T., \& Koyama, N. F. (2019). Anthropogenic influences on the time budgets of urban vervet monkeys. Landscape and Urban Planning, 181, 38-44.

Willems, E. P., \& Hill, R. A. (2009). A critical assessment of two species distribution models: A case study of the vervet monkey (Cercopithecus aethiops). Journal of Biogeography, 36(12), 2300-2312.

Willems, E. P., Barton, R. A., \& Hill, R. A. (2009). Remotely sensed productivity, regional home range selection, and local range use by an omnivorous primate. Behavioral Ecology, 20(5), 985-992.

Woodroffe, R., Thirgood, S., \& Rabinowitz, A. (2005). People and wildlife, conflict or co-existence? Cambridge: Cambridge University Press.

Yung, Y.-F., \& Chan, W. (1999). Statistical analyses using bootstrapping: Concepts and implementation. Statistical Strategies for Small Sample Research, 1, 81-105.

Zuur, A. F., Ieno, E. N., \& Elphick, C. S. (2010). A protocol for data exploration to avoid common statistical problems. Methods in Ecology and Evolution, 1(1), 3-14. 


\section{Affiliations}

Harriet R. Thatcher ${ }^{1,2} \cdot$ Colleen T. Downs $^{2}$ - Nicola F. Koyama ${ }^{1}$

$\triangle$ Harriet R. Thatcher

thatcher.r.harriet@gmail.com

1 School of Natural Sciences and Psychology, Liverpool John Moores University, Liverpool L3 3AF, UK

2 School of Life Sciences, University of KwaZulu-Natal, KwaZulu-Natal 3201, South Africa 